\title{
Effect of specimen thickness on fatigue crack growth behavior of friction stir welded 6063-T5 aluminum alloy
}

\author{
Toru TAKASE*, Atsuhiro KOYAMA*, Yuichi YAMASHITA** and Hyuma SAKI** \\ * Division of System Science, Graduate School of Engineering, Nagasaki University \\ 1-14 Bunkyomachi, Nagasaki-shi, Nagasaki 852-8521, Japan \\ E-mail: takase@nagasaki-u.ac.jp \\ ** Graduate School of Engineering, Nagasaki University \\ 1-14 Bunkyomachi, Nagasaki-shi, Nagasaki 852-8521, Japan
}

\section{Received 2 March 2016}

\begin{abstract}
In this study, the effect of specimen thickness on the fatigue crack growth behavior of the friction stir welded (FSW) joints of 6063-T5 aluminum alloy was investigated. Generally, based on microstructure characterization of welded zone, three different zones have been classified, i.e., stir zone (SZ), thermo-mechanically affected zone (TMAZ) and heat-affected zone (HAZ). The crack growth behavior in the SZ was examined. In addition, the fatigue tests on the base materials (BM) of 6063-T5 aluminum alloy were carried out. The specimens with two different thickness were prepared for both the friction stir welded joints (SZ specimen) and the base materials (BM specimen). The fatigue crack propagated along the welding direction in the SZ specimen and the rolling direction in the $\mathrm{BM}$ specimen. Fatigue tests were conducted at the stress ratio $\mathrm{R}=0.1$ under axial loading. The crack growth rate was accelerated as the specimen thickness increased and the thickness effect was more significant in the stir zone. In the SZ specimen, the crack growth rate of the thick specimen is approximately three times higher than that of the thin specimen except lower stress intensity factor range. In the BM specimen, the fatigue crack growth rate of the thick specimen is slightly higher than that of the thin specimen.
\end{abstract}

Key words : Fatigue, Crack growth, Thickness effect, Friction stir welding, Aluminum alloy

\section{Introduction}

In the present time, the energy saving is the important factor. One of the useful method to realize the energy saving is reduction in size and weight of the structure. On the other hand, the high strength is also required in structural materials. The high strength aluminum alloys are the ideal material because of its high specific strength. However it was difficult for the high strength aluminum alloys to weld. Also the mechanical properties of the welds joined by conventional welding method were lower than the base material. Therefore, the friction stir welding has received the attention.

The friction stir welding (FSW) is a new welding technique which was invented at The Welding Institute (TWI) of UK in 1991 and it has been widely used mainly for aluminum alloys. Schematic illustration of the FSW process is shown in Fig.1. In this process, a rotating tool is plunged between two clamped plates. The frictional heat is generated between the tool and the plates. The material of the plate is softened by the frictional heat and the plates are joined. Because the FSW is a solid-state joining process, it results in various advantages. The benefits include the low distortion of workpiece, the fine microstructure and absence of cracking. Moreover, the materials, for example 2000 and 7000 aluminum alloys, which are difficult to weld can be joined. Because it is expected that the applications of the FSW technique will expand to various structures, a lot of researches have been carried out on FSW technique (Tiwari et al., 2013).

Various microstructures are observed in the FSW welded zone. Based on microstructure characterization, three different zones; stirred zone (SZ), thermo-mechanically affected zone (TMAZ) and heat-affected zone (HAZ) have been classified. The microstructural changes affect the mechanical properties of every zones, therefore, many studies have been made on the microstructure. Liu et al. (1997) characterized the microstructures in the friction stir weld zone and compare them with the original 6061-T6 aluminum alloy. Sato et al. (1999) examined the microstructures associated with 


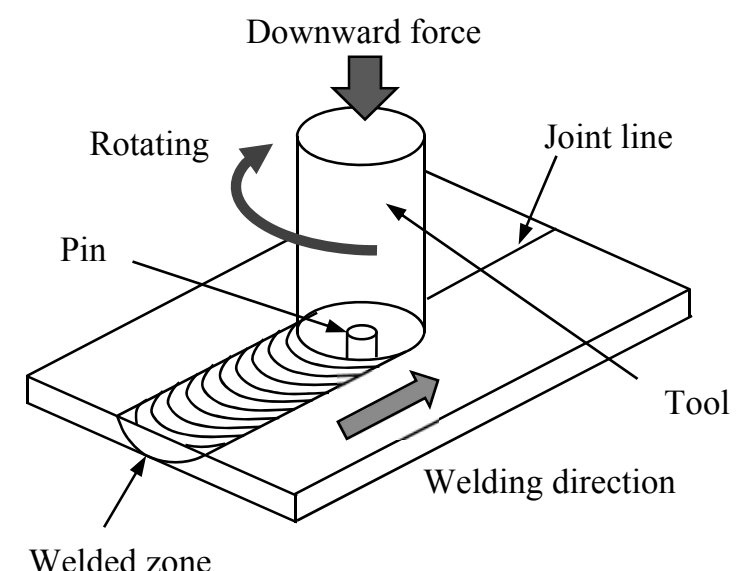

Fig. 1 Schematic illustration of friction stir welding process. A rotating tool is plunged between two clamped plates. The frictional heat is generated between the tool and the plates. The material of the plate is softened by the frictional heat and the plates are joined.

the hardness profile in a FSW welded 6063 aluminum alloy by TEM and OIM. Mahoney et al. (1998) evaluated changes in tensile properties produced by FSW joints of 7075-T651 aluminum alloy. Because the FSW tools affect the microstructure and the strength of the welded zone, the tool types, shapes, dimensions, materials and wear behaviors were evaluated (Zhang et al., 2012).

The fatigue behavior of the FSW welded joints should be researched in order to ensure the long-term reliability. Uematsu et al. (2006) investigated the fatigue behavior of the FSW joints of 6061-T6 aluminum alloy. Hagisawa and Okura (2009) revealed the effect of the stress ratio on the fatigue life and fatigue limit of the FSW welded 6005C-T6 aluminum alloy. Muzvidziwa et al. (2014) studied on the fatigue crack propagation behavior in the different zones within the FSW welded zone and estimated the effect of the microstructure on the fatigue behavior of a double-sided FSW AA6063-T5 alloy. Many other studies on the fatigue strength and crack growth behavior of FSW joints have been carried out (Moreira et al., 2008). However, there is a little research on the fatigue crack growth behavior of the thin plate joined by FSW.

In this study, the fatigue tests were conducted under the constant amplitude loading and then the effect of specimen thickness on the fatigue crack growth behavior of the base material and the friction stir welded joints of 6063-T5 aluminum alloy was investigated.

\section{Nomenclature}

$\begin{array}{ll}a & \text { Crack length [mm] } \\ \mathrm{d} a / \mathrm{d} N & \text { Fatigue crack growth rate }[\mathrm{m} / \mathrm{cycle}] \\ K & \text { Stress intensity factor }\left[\mathrm{MPam}^{1 / 2}\right] \\ \Delta K & \text { Stress intensity factor range }\left[\mathrm{MPam}^{1 / 2}\right] \\ N & \text { Number of cycles } \\ P_{\max } & \text { Maximum load }[\mathrm{kN}] \\ P_{\min } & \text { Minimum load }[\mathrm{kN}] \\ \Delta P & \text { Load range }[\mathrm{kN}] \\ R & \text { Stress ratio } \\ r_{\mathrm{p}} & \text { Plastic zone size }[\mathrm{mm}] \\ t & \text { Specimen thickness }[\mathrm{mm}] \\ W & \text { Specimen width }[\mathrm{mm}] \\ \Delta \sigma & \text { Stress range }[\mathrm{MPa}] \\ \sigma \mathrm{Y} & \text { Yield stress }[\mathrm{MPa}]\end{array}$




\section{Specimens and experimental procedure}

The materials used in this study were the base material and the friction stir welded joints of 6063-T5 aluminum alloy. The chemical composition is listed in Table 1. The FSW welded plates were purchased from Nippon Light Metal Company, Limited. Figure 2 shows the configuration and dimensions of FSW tool. The FSW tool has a tapered threaded pin profile of shoulder diameter of $20 \mathrm{~mm}$, pin diameter of $10 \mathrm{~mm}$ and pin length of $8 \mathrm{~mm}$. Two plates with a thickness of $11 \mathrm{~mm}$ were welded at a tool rotating speed of $800 \mathrm{rpm}$ and a welding speed of $400 \mathrm{~mm} / \mathrm{min}$. The photographs of the cross section of the welded plate are shown in Fig.3. Two plates were welded by double-passed process and it shows the symmetry welded microstructure in thickness direction. The welded plate was overturned about welding line after the first weld and then second weld was made so that the advancing side of first pass coincided with the retreating side of second pass. The grains in the SZ are fine by the dynamic recrystallization and its grain size are considerably finer than that of the base material (BM) as shown in Fig.3. The mechanical properties of the BM and the SZ are listed in Table 2. Mechanical properties were obtained for the tensile specimen with a diameter of $4 \mathrm{~mm}$ and a gage length of $25 \mathrm{~mm}$. The SZ specimen was manufactured from the center of the SZ so that the loading axis was parallel to the welding direction. In both the BM and the SZ, tensile strength and Young's modulus are almost same value, but $0.2 \%$ proof stress of the $\mathrm{BM}$ is higher than that of the SZ.

Table 1 Chemical composition (wt\%) of material used.

\begin{tabular}{c|c|c|c|c|c|c|c|c}
\hline $\mathrm{Si}$ & $\mathrm{Fe}$ & $\mathrm{Cu}$ & $\mathrm{Mn}$ & $\mathrm{Mg}$ & $\mathrm{Cr}$ & $\mathrm{Zn}$ & $\mathrm{Ti}$ & $\mathrm{Al}$ \\
\hline 0.42 & 0.16 & 0.00 & 0.03 & 0.46 & 0.00 & 0.00 & 0.01 & Bal. \\
\hline
\end{tabular}

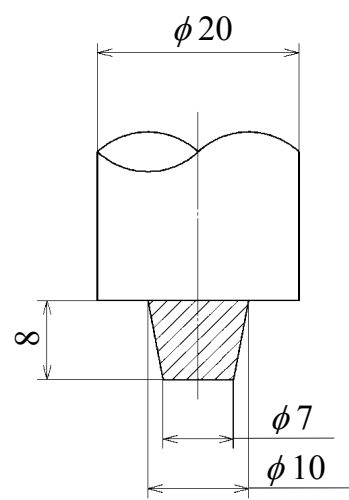

Fig. 2 Configuration and dimensions of FSW tool. The FSW tool has a tapered threaded pin profile of shoulder diameter of $20 \mathrm{~mm}$, pin diameter of $10 \mathrm{~mm}$ and pin length of $8 \mathrm{~mm}$.

Table 2 Mechanical properties of material used.

\begin{tabular}{c|c|c|c}
\hline & $\begin{array}{c}0.2 \% \text { proof stress } \\
\sigma_{0.2}[\mathrm{MPa}]\end{array}$ & $\begin{array}{c}\text { Tensile strength } \\
\sigma_{\mathrm{B}}[\mathrm{MPa}]\end{array}$ & $\begin{array}{c}\text { Young's modulus } \\
E[\mathrm{GPa}]\end{array}$ \\
\hline $\mathrm{BM}$ & 182 & 199 & 63.8 \\
\hline $\mathrm{SZ}$ & 119 & 204 & 66.0 \\
\hline
\end{tabular}




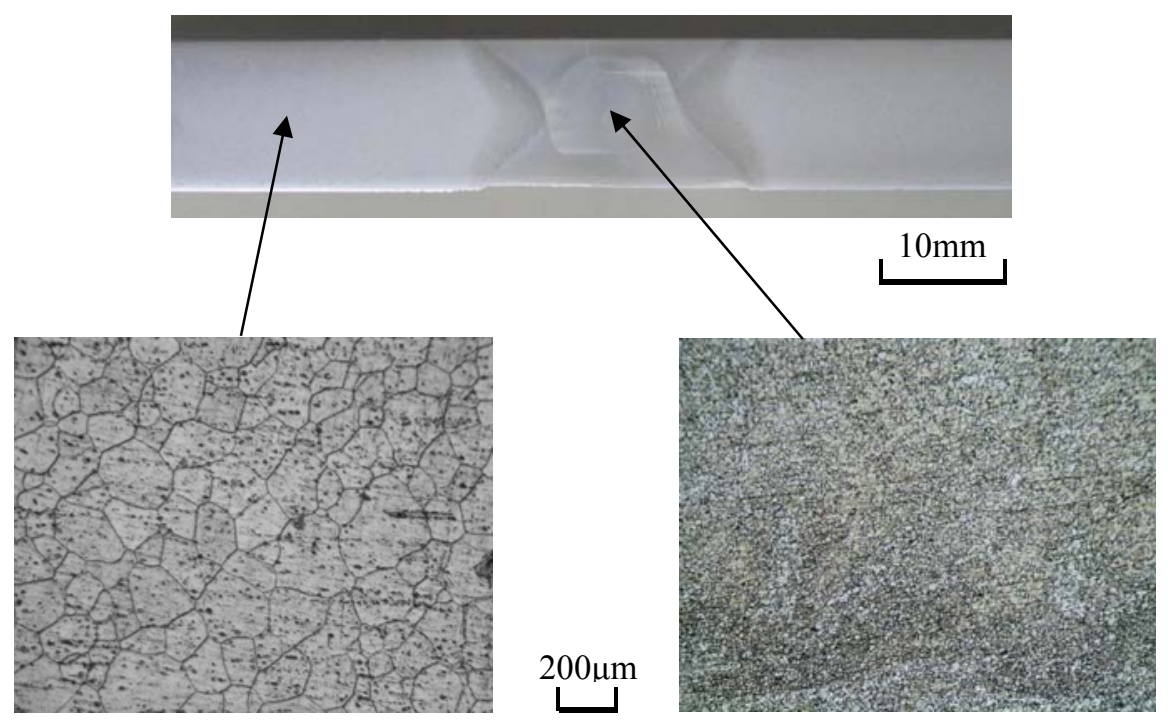

(a) BM

(b) SZ

Fig. 3 A typical macrograph consisting various microstructural zones in FSW joint. It shows the symmetry welded structure in thickness direction. The grains in the SZ are fine by the dynamic recrystallization.

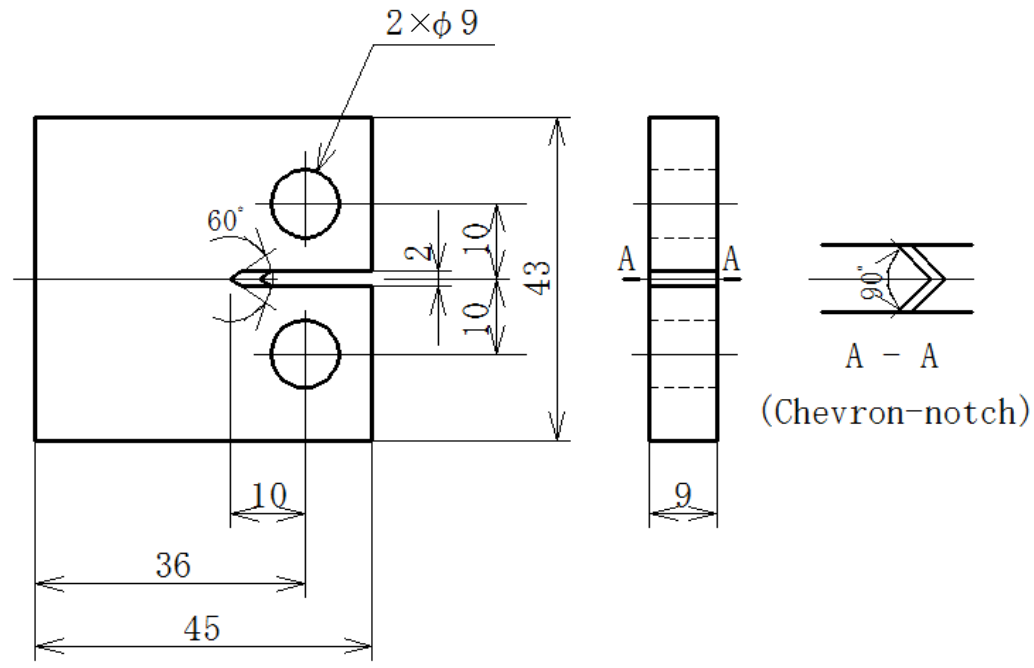

(a) CT specimen
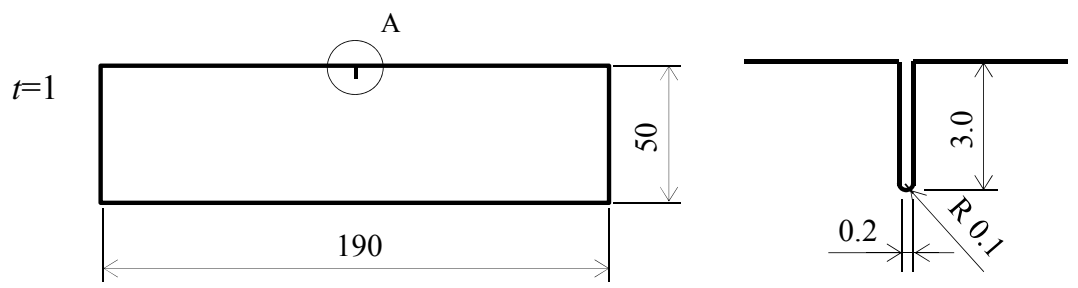

Detail of A

(b) SE specimen

Fig. 4 Configuration and dimensions of CT specimen and SE specimen. Specimen thickness of CT is $9 \mathrm{~mm}$ and thickness of SE is $1 \mathrm{~mm}$. 
The compact tension (CT) specimens and the single edge crack (SE) specimens were prepared. Figure 4 shows the configuration and dimensions of specimens. In order to initiate a crack, CT specimen had the Chevron notch with a length of $10 \mathrm{~mm}$ and SE specimen had a slit with a length of $3 \mathrm{~mm}$. Specimen thickness of CT was $9 \mathrm{~mm}$ and thickness of SE was $1 \mathrm{~mm}$. The welded plate was sliced and then machined to the required dimensions of SE specimen as shown in Fig.4 (b). The specimen, where the fatigue crack propagate along the rolling direction of the BM, was referred as the BM specimen. The specimen, where the fatigue crack propagate along the welding direction in the SZ, was referred as the SZ specimen.

Fatigue tests were carried out using the electro-servo hydraulic testing machine, the Shimadzu Servopulser series. The fatigue crack growth tests were carried out under the constant amplitude loading at the stress ratio $R=0.1$ and the sinusoidal frequency $f=3 \mathrm{~Hz}$. The fatigue pre-crack with a length of $0.3 \mathrm{~mm}$ was introduced. The fatigue crack length of CT specimen was measured by means of the unloading elastic compliance method and that of SE specimen was measured by the replica method. The crack length was defined as the length projected perpendicular to the loading axis, including the notch or the slit length.

\section{Results and discussion}

An example of the crack growth curves observed is shown in Fig.5. These are the results of the SZ and BM specimen under $P_{\max }=1.8$ and $1.5 \mathrm{kN}$ respectively. Each curve is smooth and it shows that the fatigue crack grew steadily. In other test conditions, the cracks grew steadily.

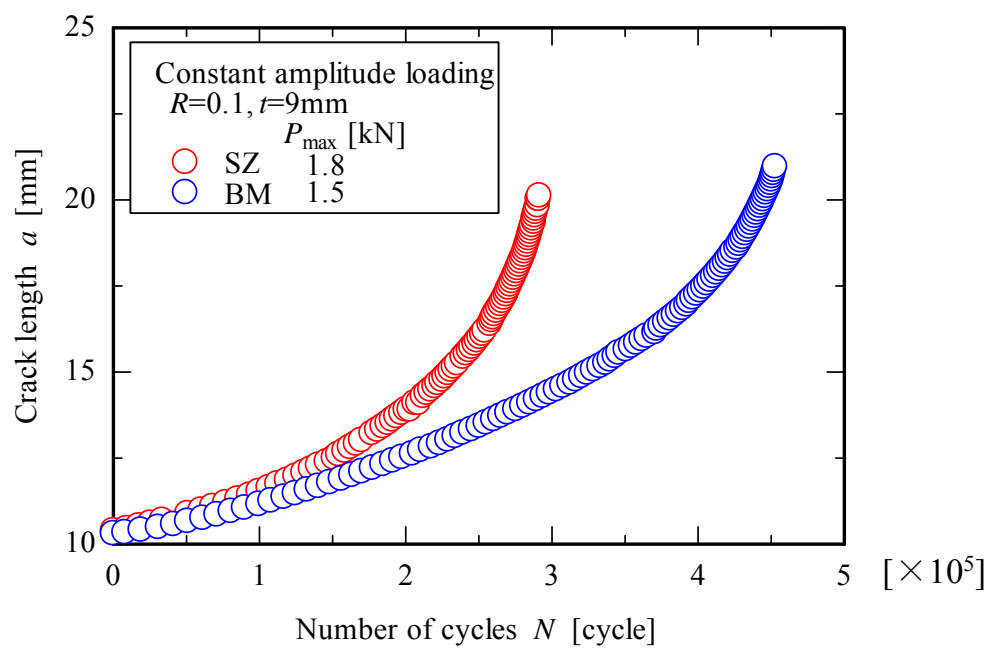

Fig.5 Crack growth curve. These smooth crack growth curves show that the fatigue crack grew steadily in each specimen.

Based on these results, the fatigue crack growth rate and the stress intensity factor range were calculated. The three point incremental polynomial method was adopted for local fitting to obtain fatigue crack growth rate and the growth rates were obtained from the first derivative of the fitted equation. The stress intensity factor range of CT specimen is determined from the expression (Murakami et.al, 1987) given in Eq. (1).

$$
\Delta K=\frac{\Delta P}{t \sqrt{W}} \cdot F(\alpha)
$$

where, $\Delta P=P_{\max }-P_{\min }$ 


$$
\begin{aligned}
& \alpha=\frac{a}{W} \\
& F(\alpha)=\frac{(2+\alpha)\left(0.886+4.64 \alpha-13.32 \alpha^{2}+14.72 \alpha^{3}-5.6 \alpha^{4}\right)}{(1-\alpha)^{3 / 2}}
\end{aligned}
$$

The stress intensity factor range of SE specimen is determined from the expression (Murakami et.al, 1987) given in Eq. (2).

$$
\Delta K=\Delta \sigma \sqrt{\pi a} \cdot F(\alpha)
$$

where, $\alpha=\frac{a}{W}$

$$
F(\alpha)=1.12-0.231 \alpha+10.55 \alpha^{2}-21.72 \alpha^{3}+30.39 \alpha^{4}
$$

The relationships between the fatigue crack growth rate $\mathrm{d} a / \mathrm{d} N$ and the stress intensity factor range $\Delta K$ for the $\mathrm{BM}$ and the SZ specimens are shown in Fig.6. The fatigue crack growth rates as a function of the stress intensity factor range on logarithmic coordinates are shown in Fig.6. In both the BM and the SZ specimens, the fatigue crack growth rate of the thin specimen $(t=1 \mathrm{~mm})$ is lower than that of the thick specimen $(t=9 \mathrm{~mm})$. Generally, a plane stress condition is dominant near the crack tip in the thinner specimens. On the other hand, in the thicker specimens, the stress state is combination of the plane stress and the plane strain conditions and the stress state more closely approaches the plane strain conditions. The stress state near the surface is the plane stress condition and the inner is the plane strain condition.

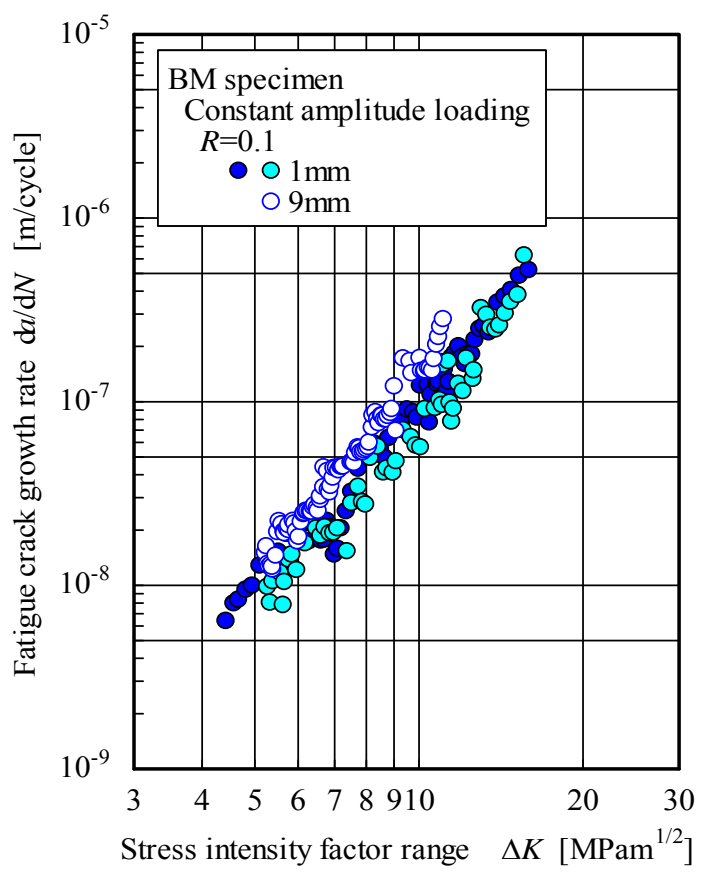

(a) BM

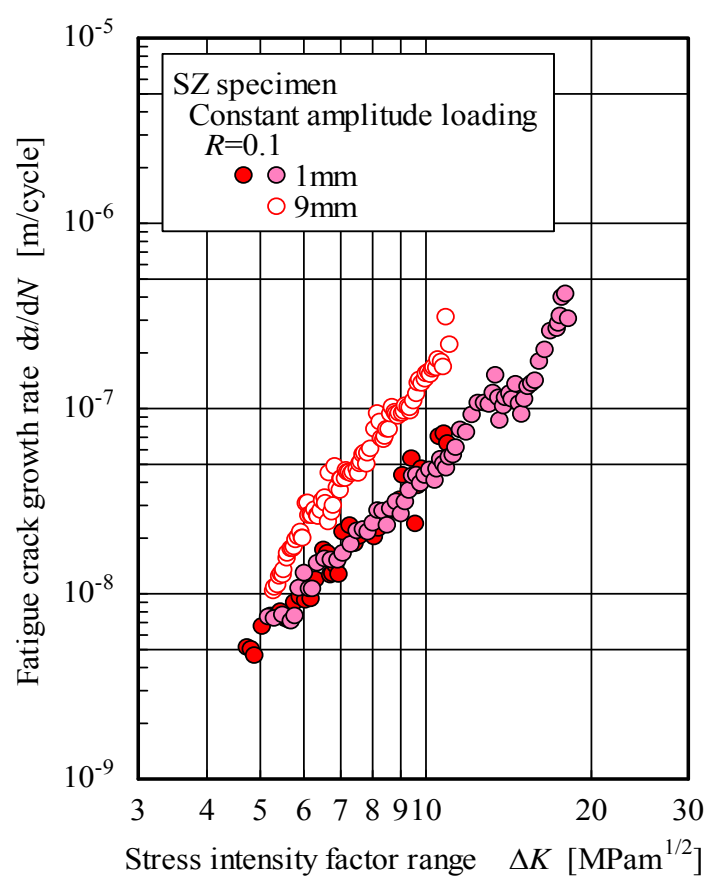

(b) SZ

Fig.6 Relationship between fatigue crack growth rate and stress intensity factor range. In both the BM and the SZ specimens, the fatigue crack growth rate of the thick specimen $(t=9 \mathrm{~mm})$ is higher than that of the thin specimen $(t=1 \mathrm{~mm})$. 
In the material with a simple elastic-perfectly plastic response, the plastic zone size ahead of the crack tip in the plane stress and plane strain condition are expressed by Eq. (3) and (4) respectively. However, $\sigma_{\mathrm{Y}}$ is replaced to $\sigma_{0.2}$ in this study.

$$
\begin{array}{ll}
r_{\mathrm{p}}=\frac{1}{\pi}\left(\frac{K}{\sigma_{\mathrm{Y}}}\right)^{2} & \text { plane stress } \\
r_{\mathrm{p}}=\frac{1}{3 \pi}\left(\frac{K}{\sigma_{\mathrm{Y}}}\right)^{2} & \text { plane strain }
\end{array}
$$

Figures 7 shows the fracture surface. In the BM, the crack front is curved in the thick specimen as shown in Fig.7 (a). It is confirmed that the crack grew slower near the surface of the specimen. In the thin specimen, the curved crack front is not observed and the crack grew uniformly through the thickness of the specimen as shown in Fig.7 (b). In the SZ, the similar behavior of the crack front is observed as shown in Fig.7 (c) and (d). It is seen that the stress state was the plane stress condition in the thin specimen and it was the plane strain condition in the thick specimen. From the above, the plastic zone size ahead of the crack tip in the thin specimen is larger than that in the thick specimen and it is assumed that this results in the lower crack growth rate in the thin specimen.

As can be seen in Fig.6 (a) and (b), the thickness effect is more remarkable in SZ specimen. In the SZ specimen, the

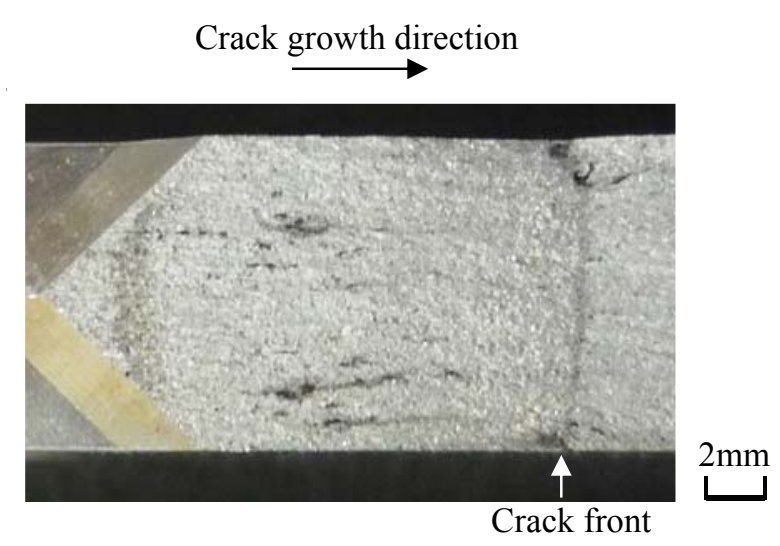

(a) BM, $t=9 \mathrm{~mm}$

Crack growth direction

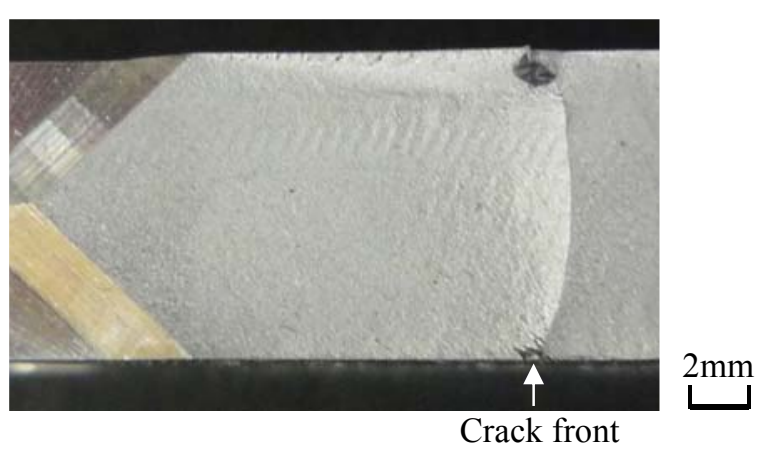

(c) $\mathrm{SZ}, t=9 \mathrm{~mm}$
Crack growth direction

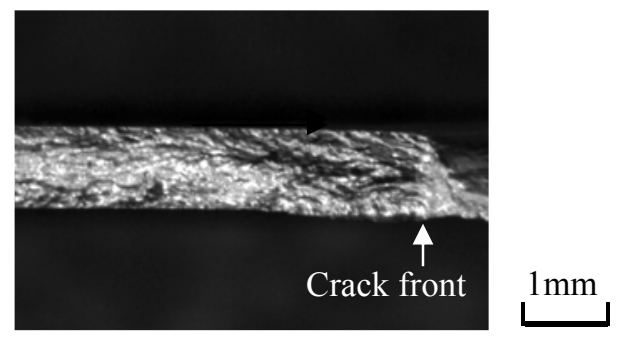

(b) BM, $t=1 \mathrm{~mm}$

Crack growth direction

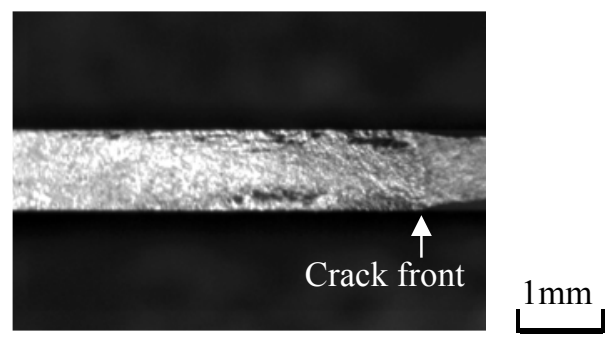

(d) SZ, $t=1 \mathrm{~mm}$

Fig.7 Fracture surface of specimens. The crack front are curved the thick specimen. The crack surface of the BM specimen is rougher than that of the SZ specimen. 
crack growth rate of the thick specimen is approximately three times higher than that of the thin specimen except lower $\Delta K$ as shown in Fig.6 (b). In the BM specimen, the fatigue crack growth rate of the thick specimen is slightly higher than that of the thin specimen as shown in Fig.6 (a). Furthermore, in thick specimen, the fatigue crack growth rate of the BM specimen and the SZ specimen is approximately the same. The fatigue crack growth rate of the thin SZ specimen is considerably lower than that of other three specimens. In this study, the plasticity-induced crack closure and the roughness-induced crack closure are considered. The large plastic zone and the large roughness may cause the lower crack growth rate. In the BM specimen, the roughness-induced crack closure is more dominant because the roughness of fracture surface is larger than that of the SZ specimen as shown in Fig.7. On the other hand, the effect of the plasticityinduced crack closure on the crack growth behavior may appear remarkably in the SZ specimen because of the lower $0.2 \%$ proof stress. In thick specimen, the effect of the plasticity-induced crack closure and the roughness-induced crack closure may be balanced and the same fatigue crack growth rate is assumed to obtain in both the BM and the SZ specimens. In the thin SZ specimen, the thickness effect on fatigue crack growth rate may appear remarkably because of the lower $0.2 \%$ proof stress and the plane stress state. Consequently, it is assumed that the fatigue crack growth rate of the thin SZ specimen become lower than that of other three specimens.

\section{Conclusion}

This study investigated the effect of the thickness on the fatigue crack growth behavior of the friction stir welded of 6063-T5 aluminum alloy. The base material specimens were also prepared. The fatigue crack growth tests were carried out under the constant amplitude loading at the stress ratio $R=0.1$. The cracks grew steadily in all test conditions. In both of the stir zone and the base material, the fatigue crack growth rate of the thin specimen is lower than that of the thick specimen. Especially, the thickness effect was remarkable in the stir zone and the crack growth rate of the thin specimen was approximately one third of the thick specimen except lower stress intensity factor range. The crack growth rate was related to the stress state ahead of the crack tip and the roughness of fracture surface.

\section{References}

Hagisawa, N. and Okura, I., Influence of Stress Ratios on Fatigue Strength of A6005C-T5 Aluminum Alloy and its Friction Stir Welded Joints, Journal of Japan Society of Civil Engineers, Ser. A1, Vol.65, No.1 (2009), pp.117-122 (in Japanese).

Liu, G., Murr, L.E., Niou, C-S., McClure, J.C. and Vega, F.R., Microstructural Aspects of the Friction-Stir Welding of 6061-T6 Aluminum, Scripta Materialia, Vol.37, No.3 (1997), pp.355-361.

Mahoney, M.W., Rhodes, C.G., Flintoff, J.G., Bingel, W.H. and Spurling, R.A., Properties of friction-stir-welded 7075 T651 aluminum, Metallurgical and Materials Transactions A, Vol.29, No.7 (1998), pp.1955-1964.

Moreira, P.M.G.P., de Jesus, A.M.P., Ribeiro, A.S. and de Castro, P.M.S.T., Fatigue crack growth in friction stir welds of 6082-T6 and 6061-T6 aluminium alloys: A comparison, Theoretical and Applied Fracture Mechanics, 50 (2008), pp.81-91.

Murakami, Y., Aoki, S., Hasebe, H., Itoh, Y., Miyata, H., Miyazaki, N., Terada, H., Tohgo, K., Toya, M. and Yuuki, R., Stress Intensity factors Handbook (1987), p.9,18, Pergamon Press.

Muzvidziwa, M., Okazaki, M., Yamagishi, S. and Seino, M., Local fatigue crack propagation behavior of a two-pass friction stir welded aluminum alloy, Bulletin of the JSME Mechanical Engineering Journal, Vol.1, No.6(2014), pp. $1-9$.

Rhodes, C.G., Mahoney, M.W., Bingel, W.H., Spurling, R.A. and Bampton, C.C., Effects of Friction Stir Welding on Microstructure of 7075 Aluminum, Scripta Materialia, Vol.36, No.1 (1997), pp.69-75.

Sato, Y.S., Kokawa,H., Enomoto,M. and Jogan,S., Microstructural Evolution of 6063 Aluminum during Friction-Stir Welding, Metallurgical and Materials Transactions, 30A (1999), pp.2429-2437.

Tiwari, S.K., Dinesh Kumar Shukla, and Chandra, R., Friction Stir Welding of Aluminum Alloys: A Review, International Journal of Mechanical, Aerospace, Industrial, Mechatronic and Manufacturing Engineering Vol.7, No.12 (2013), pp.2403-2408.

Uematsu, Y., Tokaji, K., Tozaki, Y. and Shibata, H., Fatigue Behavior of Friction Stir Welded Joints of 6061-T6 Aluminum Alloy, Journal of the Society of Materials Science, Japan, Vol.55, No.1 (2006), pp.49-54 (in Japanese). 
Takase, Koyama, Yamashita and Saki, Mechanical Engineering Journal, Vol.3, No.6 (2016)

Zhang, Y. N., Cao, X., Larose, S. and Wanjara, P., Review of tools for friction stir welding and processing, Canadian Metallurgical Quarterly, Vol.51, No.3 (2012), pp.250-261. 